\title{
STUDY OF THE IMPACT FROM DROPPING A CONTAINER FROM THE MANOEUVERING SYSTEMS ON THE MAIN DECK OF A PSV
}

\author{
Costel-Iulian Mocanu \\ "Dunarea de Jos" University of Galati, \\ Faculty of Naval Architecture, Galati, \\ Domneasca Street, No. 47, 800008, Romania, \\ E-mail: Costel.Mocanu@ugal.ro \\ Daniela-Mihaela Loică \\ "Dunarea de Jos" University of Galati, \\ Faculty of Naval Architecture, Galati, \\ Domneasca Street, No. 47, 800008, Romania, \\ E-mail: daniela.0911@yahoo.com
}

\author{
Andreea-Georgiana Darie \\ "Dunarea de Jos" University of Galati, \\ Faculty of Naval Architecture, Galati, \\ Domneasca Street, No. 47, 800008, Romania, \\ E-mail: darie.andreeag@yahoo.com \\ Alin Pohilca \\ "Dunarea de Jos" University of Galati, \\ Faculty of Naval Architecture, Galati, \\ Domneasca Street, No. 47, 800008, Romania, \\ E-mail: Alin.Pohilca@ugal.ro
}

\begin{abstract}
The topic approached in this paper regards the impact between a container dropped from the manoeuvering systems and main deck of a PSV, without considering the wood material. This study was done to verify the structural resistance of the deck in the most difficult conditions of loading and unloading containers.

The dropping test of the container is pretty difficult because it involves a detailed analysis of the stresses that occur in the deck's structure, as well as in the container's structure.
\end{abstract}

Keywords: container, stress, deformation, PSV.

\section{INTRODUCTION}

One of the important opportunities offered by platform supply vessels is that theycan allow the transport of goods that are suitable for containerization. Thus, a number of containers can be transported on the main deck, for which special fastening systems have been produced.

Container transport is considered to be one of the most efficient means of transport for goods worldwide, since the risk of damage is minimal and the cost of handling is low.

For loading/ unloading operations of containers, adequate equipment must be used to ensure safe transfer. Supply vessels must be equipped with one or two cranes, but most often the platforms are equipped with the tools required for manoeuvering.

There have been situations where, for various reasons, the containers dropped from the manoeuvering systems, effectively collapsing on the deck with adverse consequences on the integrity of the structure. Most of the times, the wood on the main deck does not provide sufficient protection.

\section{CONTENT}

The proposed research was carried out for a platform supply vessel, PSV5000. The main dimensions of the ship may be seen in Table 1. 
Table 1. Main characteristics

\begin{tabular}{|l|c|}
\hline Length over all, $L_{O A}[\mathrm{~m}]$ & 85.6 \\
\hline $\begin{array}{l}\text { Length between perpendiculars, } L_{B P} \\
{[\mathrm{~m}]}\end{array}$ & 79.25 \\
\hline Beam, $B[\mathrm{~m}]$ & 22 \\
\hline Depth, $D[\mathrm{~m}]$ & 8.5 \\
\hline Draft, $T[\mathrm{~m}]$ & 6.7 \\
\hline Displacement, $\Delta[\mathrm{t}]$ & 9668 \\
\hline Design speed, $v[\mathrm{Nd}]$ & 14.5 \\
\hline Block coefficient, $C_{B}$ & 0.776 \\
\hline
\end{tabular}

\subsection{Material Selection}

One of the major considerations for the hull structure of the ship is the material of construction. Steel remains the most popular material for ship structures. Two categories of steel are considered: normal hull structural steel grade A and high tensile hull structural steel grade AH36. AH36 steel has a nominal yield stress of $355 \mathrm{MPa}$ and a breaking limit of 490 - $630 \mathrm{MPa}$.

\subsection{PSV's Structure Modeling}

In order to accomplish the proposed study, the structure of the deck and the structure of the container were generated. The thickness of the longitudinal and transverse members and transverse are shown in Table 2 .

Table 2. The thicknesses of the structural elements

\begin{tabular}{|l|c|}
\hline Bottom plating [mm] & 10 \\
\hline Double bottom plating [mm] & 12 \\
\hline Deck plating [mm] & 9 \\
\hline Shell plating [mm] & 12 \\
\hline Bottom longitudinals plating [mm] & $140 \times 8$ \\
\hline Tank top longitudinals plating [mm] & $180 \times 9$ \\
\hline Deck longitudinals plating [mm] & $140 \times 8$ \\
\hline
\end{tabular}

The structure was generated in AutoCad.

Geometry was imported into the Explicit Dynamics module provided by Ansys Workbench.

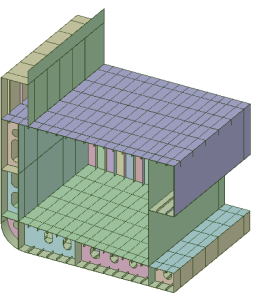

Fig. 1. Model isometric view

\subsection{Container particulars}

The ships structure was studied using a 20 TEU container. Its dimensions are shown in Tabel 3.

Table 3. Container dimensions

\begin{tabular}{|l|c|}
\hline External dimensions [mm] & $6058 \times 2438 \times 2591$ \\
\hline Internal dimensions [mm] & $5898 \times 2352 \times 2393$ \\
\hline Own weight $[\mathrm{t}]$ & 2.2 \\
\hline Load weight $[\mathrm{t}]$ & 24 \\
\hline Volum $\left[\mathrm{m}^{3}\right]$ & 33.2 \\
\hline
\end{tabular}

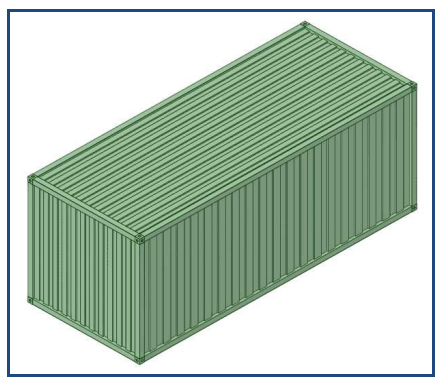

Fig. 2. Container's structure

\section{STRENGTH ANALYSIS USING FINITE ELEMENT METHOD}

The studied model was analyzed in the absence of double shell structures, apply-ing the suitable boundary conditions.

Following meshing was obtained a network of quadrilateral quad type, whose size varies according to the body surface, having an average size of $50 \mathrm{~mm}$. The result was a number of 30210 elements and 29869 nodes. The discretization of the deck and container structure is shown in the figure. 


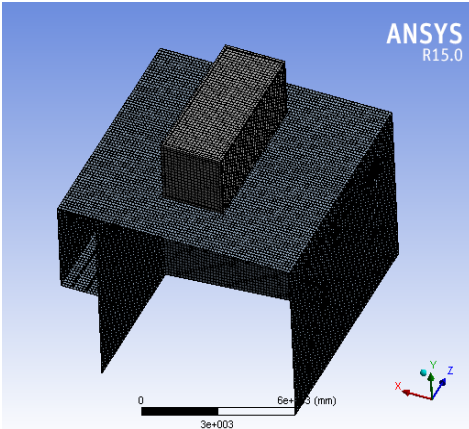

Fig. 3. Meshed structure

\subsection{Boundary conditions and loads}

As for boundary conditions, in the Center Plane the symmetry conditions were applied. On the contour of the fore and aft of the model, the translation in the $\mathrm{y}$ direction and the rotation in the $\mathrm{z}$ direction are free. At the bottom, where the structure is welded to the double bottom plating, all translations and rotations are blocked.

It was considered fully loaded container, and so a force of $240 \mathrm{KN}$ distributed on the surface of the lower four corner pieces of the container was applied. Also, the gravitational acceleration was defined to take into account the weight of the structure itself.

Impact analysis requires the declaration of a linear velocity, which is determined by the height of fall and the gravitational acceleration. The structure of the container was placed at a distance of $100 \mathrm{~mm}$ from the deck and it was applied a speed of $5 \mathrm{~m} / \mathrm{s}$, calculated for a height of $1.25 \mathrm{~m}$.

Several cases were considered for the impact of the container with the deck.

\subsection{Ideal case}

After running the program, it was found that the stress of the analyzed structure in the ideal case had values between $0.154 \mathrm{MPa}$ and 328.1 MPa. This situation is not dangerous because the yield stress is not exceeded, and therefore the deck has no plastic deformations.

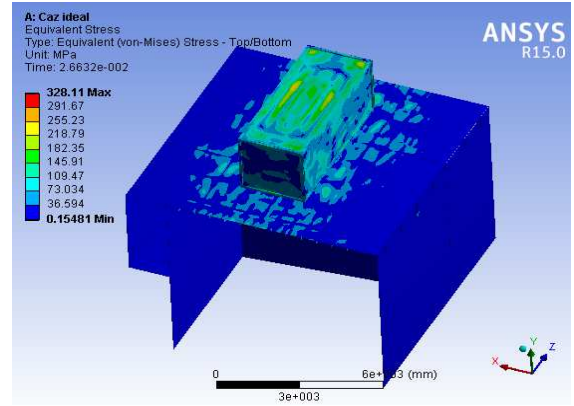

Fig. 4. Stress analysis results

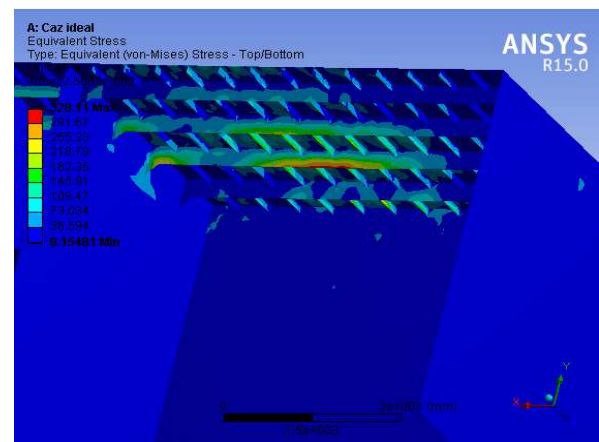

Fig. 5. Maximum stress area

\subsection{Case 2 - The lateral edge of the container is the one that strikes first the deck}

In this case the structure present stresses between $0.199 \mathrm{MPa}$ and $486.31 \mathrm{MPa}$ and deformations values between 0 and 210.53 $\mathrm{mm}$. It is noted that the deck structure successfully resists exploitation.

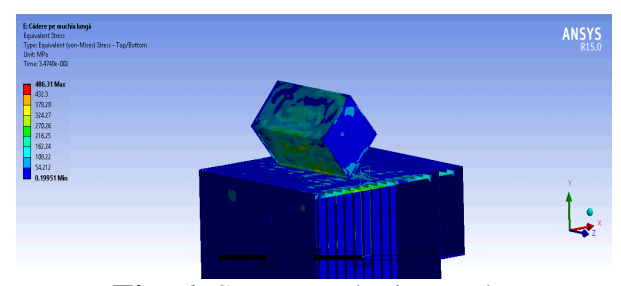

Fig. 6. Stress analysis results 


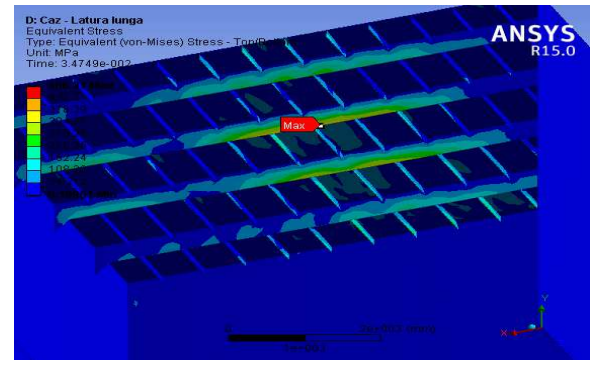

Fig. 7. Maximum stress area

\subsection{Case 3 - the front edge of the container is the one that strikes first the deck}

The maximum stress of $669.79 \mathrm{MPa}$ is detected in the container structure near the corner pieces. The deformations found are between 0 and $426.9 \mathrm{~mm}$. By evaluating the results it can be stated that the structure of the container is the one that fails structurally.

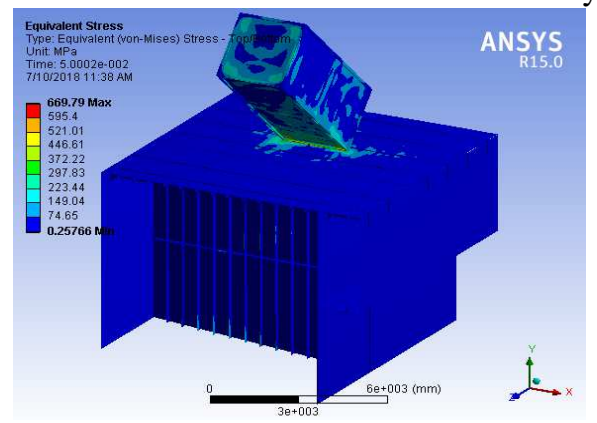

Fig. 8. Stress analysis results

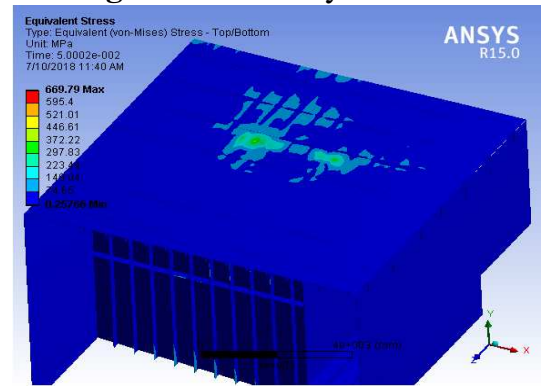

Fig. 9. Maximum stress area

\subsection{Case 3 - Fall on the corner}

The maximum values are identified in the deck stiffners, located near the collision zone. The total deformation is between 0 and
569.2 MPa. To avoid structural failure, the thickness and quality of wood used for protection should be chosen rationally. Another solution would be to dimension the deck stiffening elements according to the results obtained.

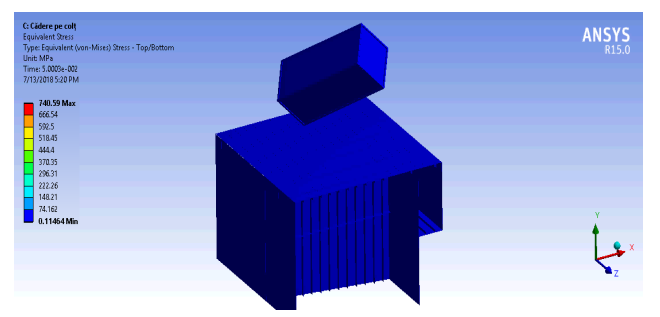

Fig. 10. Stress analysis results

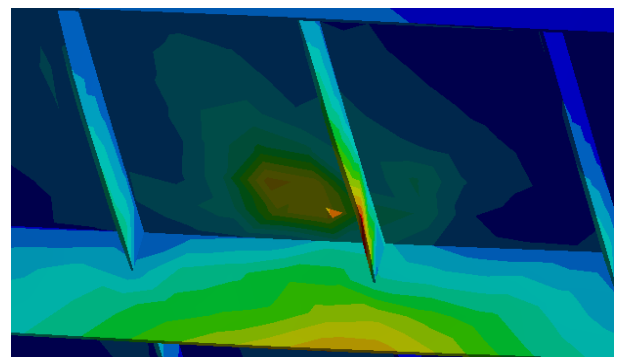

Fig. 11. Maximum stress area

\section{CONCLUDING REMARKS}

The distribution of the stresses resulted from the generation of the finite element analysis allows selecting the critical structural regions, and therefore indicates the necessity for the following solutions: increased attention to the selection of the material placed on the deck, the increase of the deck thickness, the choice of some profiles that increase resistance. These solutions must be carefully considered in terms of both the weight of the ship and the costs involved.

\section{REFERENCES}

[1]. Ovidiu Ionaș, "Nave tehnice”, Galati Unversity Press (GUP), 2014.

Paper received on December $31^{\text {th }}$, 2018 